\title{
Readiness of the ASEAN Community for the 4th Industrial Revolution
}

\author{
Pornpen Vora-Sittha ${ }^{1} \&$ Apirada Chinprateep ${ }^{1}$ \\ ${ }^{1}$ School of Development Economics, National Institute of Development Administration, Bangkok, Thailand \\ Correspondence: Pornpen Vora-Sittha. E-mail: pornpen_econ@yahoo.com
}

Received: October 21, 2020

Accepted: December 25, 2020

Online Published: January 22, 2021

doi:10.5539/ass.v17n2p31

URL: https://doi.org/10.5539/ass.v17n2p31

\begin{abstract}
The study explores the readiness of ASEAN Community for the world Fourth Industrial Revolution, and to propose policy suggestions for stakeholder perspectives. The methodology used is SWOT and TOWS analysis. The results of the study show that only Singapore is the readiest country to face 4IR. Rest of ASEAN members moderately prepared for the world 4IR, except Brunei, Cambodia, Laos, and Myanmar. The size of the ASEAN digital economy has the opportunity to be ranked as the world's top five in 2025 , drive-by e-commerce, large industrial plants with the participation of small and medium enterprises. Singapore may face employment disruption before other countries because of its most advanced in using AI technology.
\end{abstract}

Keywords: 4IR, industrial revolution, ASEAN, Thailand, SWOT, TOW, digital, disruption

\section{Introduction}

Industrial Revolution 4.0 (IR 4.0) represents the movement towards smart industry and manufacturing goals. ASEAN countries, including Thailand, are experiencing industrial transformation on an unprecedented scale with automation, data exchanges, cloud computing, cyber-physical systems, robots, big data, artificial intelligence, the internet of things, and semi-autonomous industrial techniques. Compared with previous industrial revolutions, the fourth is evolving at an exponential pace. And, the breadth and depth of these changes herald the transformation of entire systems of production, management, and human resources. Like every industrial revolution, there has been a requirement for a skill change, and higher education to handle new technologies and embrace IR 4.0.

This study explores the readiness of the ASEAN Community for the world Fourth Industrial Revolution, and to propose policy suggestions for stakeholder perspectives.

\section{Methodology and Analytical Framework}

This study assesses the readiness of the ASEAN Community for the world 4IR by using SWOT analysis and TOWS matrix analysis. SWOT analysis is a strategic planning technique. It helps identify internal and external factors (Dess, 2018). These factors can be favorable or unfavorable for ASEAN to cope with the IR4. A SWOT matrix here is summarized as follow:

a) Strengths: The strengths within ASEAN countries.

b) Weaknesses: The weaknesses within ASEAN countries.

c) Opportunities: What opportunities from the external sources exist for the ASEAN countries.

d) Threats: The obstacles that ASEAN countries face from external sources.

A TOWS matrix is to help the collected information in the SWOT matrix to come up with strategic options that link the external factors to the internal factors. There are four categories of strategy derived from a TOWS matrix (Watkins, 2007).

a) Strengths and Opportunities ( $\mathrm{SO}$ ): Strategies that use strength to take advantage of an opportunity from outside.

b) Weaknesses and Threats (WT): Strategies that try to minimize weaknesses and avoid threats.

c) Strengths and Threats (ST): Strategies that maximize a strength to minimize a threat.

d) Weaknesses and Opportunities (WO): Strategies that use an opportunity to overcome a weakness.

How SWOT becomes TOWS Matrix can be shown as follow: 

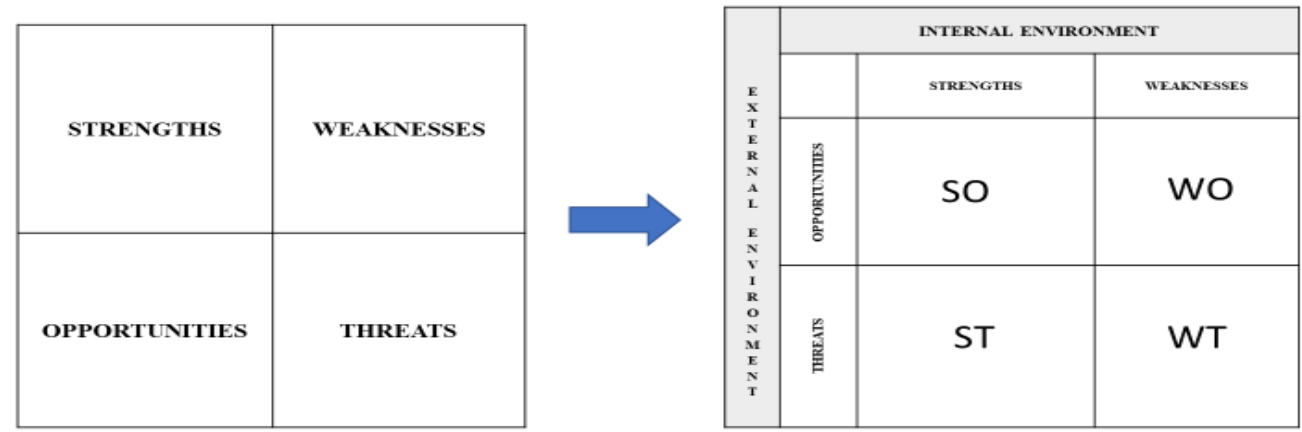

\section{The Data and Scope of Study}

This study uses secondary data from several sources such as ASEAN Secretariat, International Development Research Centre, the world bank, Google, Temasek Holdings, EF English Proficiency Index, Oxford Economics, Temasek, McKinsey, Government websites, Google, etc. The analysis in this study intends to cover 10 ASEAN communities. Due to data limitation, some analysis may not cover data for all ten countries.

\section{Review of Previous Study}

\subsection{The Fourth Industrial Revolution}

A technological revolution fundamentally alters the way we live, work, and relate to one another. The First Industrial Revolution used water and steam power to mechanize production. The Second used electric power to create mass production. The Third used electronics and information technology to automate creation. Now a Fourth Industrial Revolution (4IR) is building on the Third. It is the digital revolution, occurring since the middle of the last century.

When compared with previous industrial revolutions, the Fourth is evolving at an exponential rather than a linear pace (Perrault et al., 2018). It involves a paradigm shift from mass production to mass customization, centralized to decentralized decision making, and fully-integrated and collaborative manufacturing systems that respond in real-time to changing demands and conditions in the factory, in the global supply and value chains, and to customer needs. Also, it integrates a set of convergent technologies that create manufacturing systems (Note 1), and integrated smart products using advanced materials and services, leading to smart factories, smart manufacturing, and smart industries (UNIDO, 2019).

\subsection{The Role of Artificial Intelligence (AI) in the 4IR}

The Stanford Institute for Human-Centered Artificial Intelligence (2019) defines AI as a set of algorithms and methodologies to process data and improve the precision and response time to make or support the decision in classification, forecast, etc. It continues to get smarter and more pervasive, eventually surpassing human capacities in speed and precision, though never quite the same as human beings.

Among the emerging technology, artificial intelligence (AI) is already around us, from self-driving cars and drones to digital assistants, which help users perform various tasks, such as checking their schedules and searching for something on the web to sending commands to another app. AI is an essential part of how these applications work because they learn from every single user interaction, and allows them to recognize speech patterns better and serve users results tailored to their preferences. (Klaus Schwab, 2016).

The AI Index report finds that commercial and research work in AI, as well as funding, is exploding pretty much everywhere. There's an unusually high concentration in Europe and Asia, with China, Japan, and South Korea leading Eastern countries in AI research paper publication, university enrollment, and patent applications. Besides, the report also finds that AI development is mainly a struggle between the US and China, and with some other prominent countries such as Finland excels in AI education, India demonstrates significant AI skill penetration, Singapore has well-organized government support for AI, and Israel shows a lot of private investment in AI startups per capita (The Stanford Institute for Human-Centered Artificial Intelligence, 2019)

Several advanced economies, most prominently, Germany, the United States of America, Japan, and the Republic of Korea, have formulated strategies for fostering the uptake of the fourth industrial revolution (4IR) technologies to enhance global industrial competitiveness. Increasingly, companies are applying innovative solutions through the deployment of Industry 4.0 technologies, such as Industrial Artificial Intelligence (IAI), the Industrial Internet of Things (IIoT), cloud computing, data analytics, miniaturization, sensors and additive 
manufacturing (3D printing), as well as new materials stemming from the advancement of convergent technologies and sciences (nanotechnology, biotechnology, information technology, and cognitive and social sciences - NBICS).

\subsection{The Government Artificial Intelligence Readiness Index (Note 2)}

AI has the power to transform the way that governments around the world deliver public services. In 2017, Oxford Insights (2019) created the world's first "Government AI Readiness Index," to answer the question: how well placed are national governments to take advantage of the benefits of AI in their operations and delivery of public services? The results sought to capture the current capacity of governments to exploit the innovative potential of AI.

According to the findings, the governments of countries in the Global North earn more advantage of AI's gains than those in the Global South. Therefore, there is likely that countries in the Global South could be left behind by the fourth industrial revolution. Not only will they not reap the potential benefits of AI, but there is also the danger that unequal implementation widens global inequalities. However, the report also shows that if accelerating AI development without taking care of ethics and safe public services, AI may give the worst results for the economy and society. Therefore, the government should proceed with caution. The purpose of the assessment and rating readiness is to encourage all governments to prepare themselves as much as possible.

\subsection{Job Disruption}

The World Economic Forum predicts that significant disruption from the 4IR can be the result of automation and artificial intelligence, which eliminate many jobs and drastically reshaping others. Automation is emerging as a significant threat to jobs. Jobs in factories are more vulnerable to automation than those in IT companies because it is easy to automate manufacturing. The information technology (IT) sector seems to be the least-hit by automation. In manufacturing and engineering, jobs affected by automation are lost permanently. In contrast, in industries like IT, e-commerce, and startups, people who lose their jobs can get upskilled to other jobs (The Economic Times, Jun 28, 2017).

In terms of job replacement by AI, the Artificial Intelligence Index Report 2019 (Standford Human-Center Intelligence, 2019) found that the impact from AI does not appear as an entirely negative consequence if different types of jobs are successfully promoted. The report shows that the AI hiring rate has been increasing across all the sampled countries. They include not just advanced economies, Singapore, Brazil, Australia, Canada, and India, but also several emerging markets that experienced the fastest growth in AI hiring from 2015 to 2019. In the USA, shares of total jobs posting online (Machine Learning jobs) increased from $0.07 \%$ in 2010 to over $0.51 \%$ in October 2019 of total jobs posted in the US, followed by Artificial Intelligence jobs $(0.28 \%)$, Neural networks $(0.13 \%)$, NLP $(0.12 \%)$, Robotics $(0.11 \%)$, and Visual Image Recognition $(0.10 \%)$.

Also, e-commerce companies and startups hold a lot of jobs potential. E-commerce can create a net 12 million new jobs across the country over the next ten years, according to a research report by HSBC. With the rise of online purchases, e-commerce could create 20 million 'gross' jobs across logistics \& delivery (70\%), customer care, and IT \& management (30\%) (The Economic Times, Jun 28, 2017).

For penetration of AI skills (Note 2), The USA, China, and India increase their importance in the global economy. An exciting example is India. The average penetration of AI skills in India in selected sectors is 2.6 times the global average across the same set of occupations. It is interesting to note that India is expected to add over 10 million new young people to the labor force every year over the next decade (Economic Times, 2018). The top five sectors with the highest AI skill penetration globally are: Software \& IT Services, Hardware and Networking, Education, Finance, and Manufacturing (Standford Human-Center Intelligence, 2019, Figure 4.1.6).

\section{The ASEAN Background}

\subsection{ASEAN Economic Potential}

The AEC with ten member countries has a combined population of approximately 649.1 million people in 2018, accounting for $8.6 \%$ of the world's population. ASEAN's overall economic performance remains robust. With a combined GDP of USD 3.0 trillion in 2018, as compared to USD 2.5 trillion in 2015, ASEAN is currently the fifth-largest economy in the world. As a global trade powerhouse, the region's total trade reached USD 2.8 trillion in 2018, an increase of $23.9 \%$ from the 2015 figure of USD 2.3 trillion. The area also attracted USD 154.7 billion worth of investment in 2018 - the highest in history - and a 30.4\% increase from total FDI inflows of USD 118.7 billion in 2015.

ASEAN as a world high potential economic group continues to contribute towards the region's emerging position 
as a global growth driver, with intra-ASEAN accounting for the largest share of ASEAN's total trade and FDI inflows in 2018 at $23.0 \%$ and $15.9 \%$, respectively. (The ASEAN Secretariat, 2019, p.xiv). The digital economy of ASEAN is 7\% of ASEAN GDP and is one of the world centers of industrial production. It has an average economic growth rate of 5.3 percent per year continuously since 2000, higher than the world growth rate of 3.8 percent (CHAN CHUN SING, 2018). The forecast growth rate of gross domestic product at Fixed price in year B.E. ASEAN's 2019 will be $5.2 \%$ higher than the emerging and developing economies of $4.7 \%$ and the world at $3.7 \%$, as shown in Table 1.

Table 1. The Growth Rate of Real Gross Domestic Product in ASEAN

\begin{tabular}{ccccc}
\hline & 2016 & 2017 & $2018 \mathrm{f}$ & $2019 \mathrm{f}$ \\
\hline Global & 3.0 & 3.7 & 3.7 & 3.7 \\
Advanced Economies & 1.7 & 2.3 & 2.4 & 2.1 \\
Emerging and developing economies & 4.0 & 4.7 & 4.7 & 4.7 \\
ASEAN & 4.8 & 5.3 & 5.1 & 5.2 \\
\hline
\end{tabular}

Source. ASEAN Secretariat (August 2018); Asian Development Bank (September 2018); International Monetary Fund (October 2018)

Note. ASEAN Secretariat data is based on year-on-year growth rates of GDP in national currencies, in constant price; "f" represents forecast.

Regarding the outbreak of coronavirus, the coronavirus COVID-19 is affecting 218 countries and territories around the world with 75,130,608 cases (December 16, 2020). With more than 600 million people in the region, only 1.83 percent are the cases in ASEAN. The average cases per million people in ASEAN is 269.40 far less than the world of 9632 (Johns Hopkins University and Southeast Asian Health Ministries).

Even though the COVID-19 impact on ASEAN countries is less than the impact on the world, economic growth in Southeast Asia remains under pressure of COVID-19 outbreaks, because their economic growth rates depend mostly on world imports. The subregion's growth forecast for 2020 is revised down to $-4.4 \%$ from $-3.8 \%$ in September. The subregion's outlook for 2021 is also downgraded, with Southeast Asia now expected to grow 5.2\% next year compared to the $5.5 \%$ growth forecast in September.

\subsection{Economic Integration Through the AEC Blueprint}

Towards 2025, the region's economic integration agenda is guided by the AEC Blueprint 2025. The AEC Blueprint 2025 envisions five interrelated and mutually reinforcing characteristics, namely: (1) a highly integrated and cohesive economy; (2) a competitive, innovative, and dynamic ASEAN; (3) enhanced connectivity and sectoral cooperation; (4) a resilient, inclusive, people-oriented, and people-centered ASEAN; and (5) a global ASEAN. Most notable, under the AEC Blueprint 2025, a competitive, innovative, and dynamic ASEAN to cope with the 4IR also included. The policy focus on developing a policy environment supportive of innovation and improves productivity in the region. Besides, it also strengthens ASEAN's participation in global value chains, enhances sectoral cooperation, promotes inclusivity and sustainability. The policy includes support to micro, small, and medium enterprises (MSMEs), and encourages a more proactive role in the global economy (The ASEAN Secretariat, 2019, p. xiii).

\subsection{Government Artificial Intelligence (AI) in ASEAN}

The development of AI is an important technology to identify the country's 4IR success. The IDRC uses the Government Artificial Intelligence Readiness Index to measure government readiness in dealing with AI. The report shows that the government in ASEAN well prepare to cope with artificial intelligence (AI) than the world average and the Asia Pacific, with Singapore, Malaysia, the Philippines, and Thailand being the key drivers (Table 2).

Table 2. Government Artificial Intelligence Readiness Index

\begin{tabular}{cccc}
\hline World Rank & ASEAN Rank & Country & Index \\
\hline 1 & 1 & Singapore & 9.186 \\
22 & 2 & Malaysia & 7.108 \\
50 & 3 & Philippines & 5.704 \\
56 & 4 & Thailand & 5.458 \\
\hline
\end{tabular}




$\begin{array}{cccc}57 & 5 & \text { Indonesia } & 5.420 \\ 70 & 6 & \text { Vietnam } & 5.081 \\ 121 & 7 & \text { Brunei Darussalam } & 3.143 \\ 125 & 8 & \text { Cambodia } & 2.810 \\ 137 & 9 & \text { Laos } & 2.314 \\ 159 & 10 & \text { Myanmar } & 1.385 \\ & \text { Average of ASEAN 10 Countries } & & \mathbf{4 . 7 6 1} \\ & \text { Average of Asia-Pacific 54 Countries } & \mathbf{3 . 5 5 8} \\ & \text { Average of World 194 Countries } & \mathbf{4 . 0 3}\end{array}$

Source. IDRC (2019). Government Artificial Intelligence Readiness Index, pp. 32-37

\subsection{Positive Sign in Population Structure}

ASEAN population structure is ready to be accelerated to digital growth. With more than 600 million people in the region, about 50 percent of them are at the age between 20-54 in the year 2017, classifying as the age of ready to be accelerated to digital growth (Figure1). Also, ASEAN's middle class is expected to more than double in size from 135 million (24\% of ASEAN's population) to 334 million (51\% of the population) by 2030 (Moddle Class and Homi Kharas, 2019).

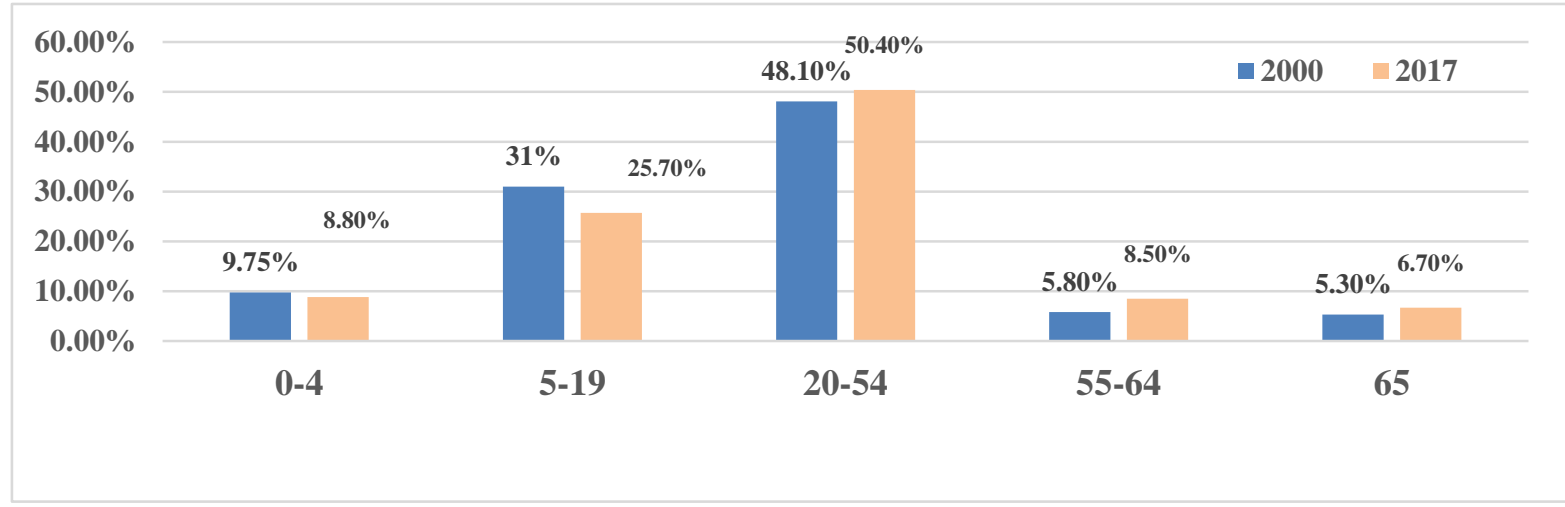

Figure 1. Population structure in ASEAN during 2000-2017

Source. The ASEAN Secretariat, 2018.

Note. Total ASEAN here excludes Singapore's non-resident population.

\subsection{Benefits Earned from The Digital Economy Via the Internet}

ASEAN is the fastest-growing internet market in the world. With over 125000 new users. It has the potential to develop and control the benefits of the digital economy via the internet. The World Bank and Google estimates that the number of internet users at least six countries, namely Thailand, Indonesia, Vietnam, Philippines, Malaysia, and Singapore, should be double in the year 2020 from 2015 (Figure 2)

\subsection{Promising Size of ASEAN E-Commerce Market}

Several countries in ASEAN, such as Thailand and Indonesia, use the internet on average 4.2 and 3.9 hours per day, respectively; the highest record in the world, while Americans use the internet for only 2 hours a day. This phenomenon reflects the potential for the development and control of the benefits of the digital economy. Besides, the number of internet users in ASEAN has almost doubled during the year 2015-2020 in each country (as shown in Figure 3), shows a strong foundation that ASEAN is capable to participate in Industry 4.0. In 2016, Google and Temasek predicted that ASEAN's e-commerce market would expand more than three times in 2020, and there is an opportunity to grow to $\$ 88000$ million by 2025 (Figure 3)

However, rapid E-Commerce expansion is considered a threat to the local wholesalers and retailers that are unable to cope with the changing world. Of which the main driving force of e-commerce for the region is currently the presence of foreign shopping portals such as Alibaba, which owns Lazada, Shopee, and Tokopedia. 


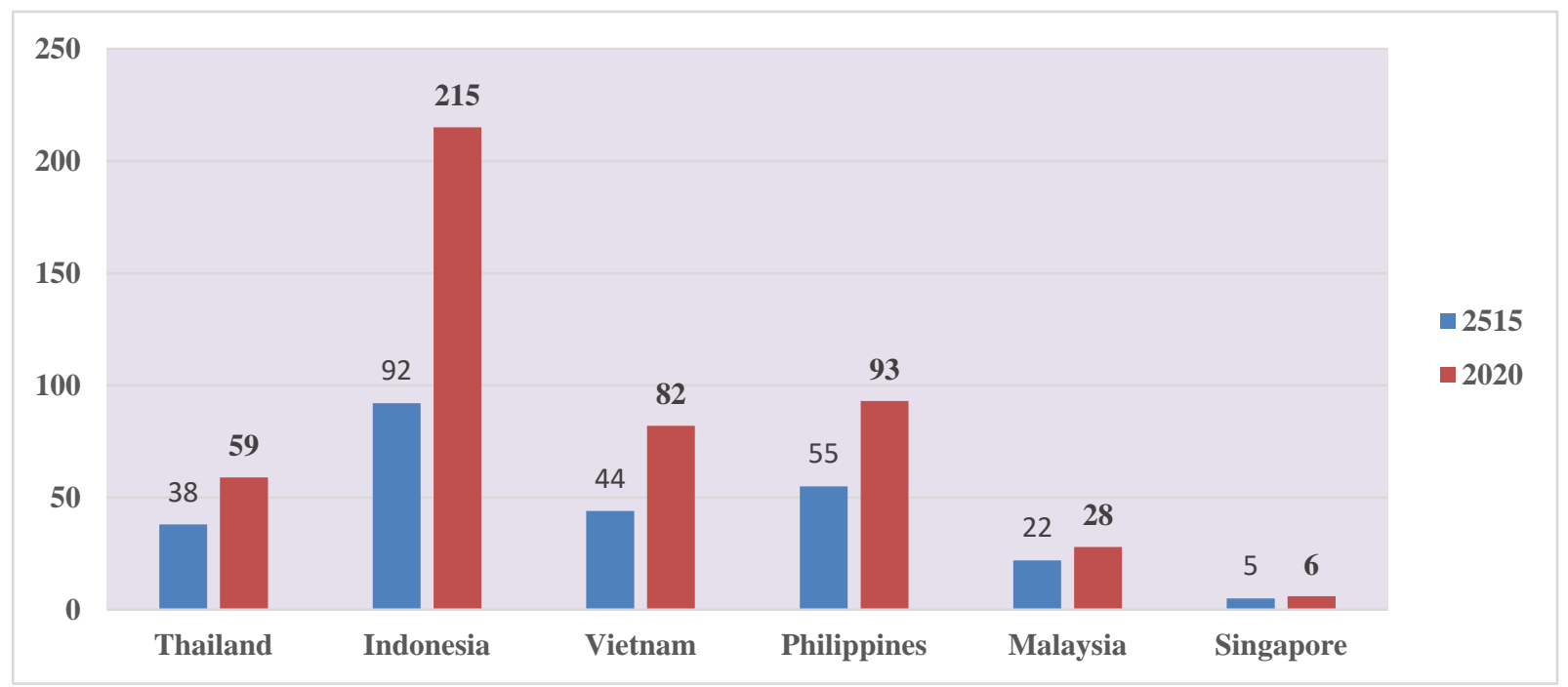

Figure 2. Internet User by Country in ASEAN

Source. World Bank, Google.

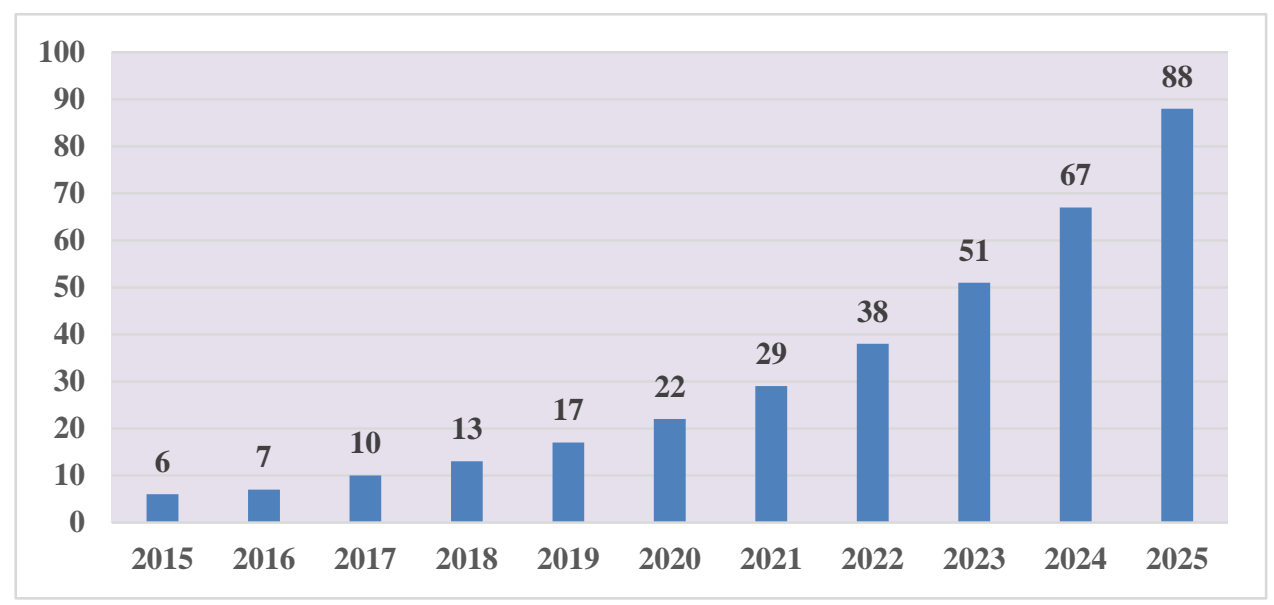

Figure 3. Estimated Size of Southeast Asia's E-Commerce Market (in Billions,USD)

Source. Google, Temasek Holdng, 2016.

\subsection{Financial Sector in ASEAN}

The six-member countries, namely Indonesia, Malaysia, Philippines, Thailand, Singapore, and Vietnam, aiming to consolidate the financial group by 2020, this enables the same standard of financial services in the member countries, such as the banking system, payment systems, insurance, and capital markets, etc. The proper standard financial sector will help support the expansion of trade and international investment in the region, which leads to the development of the real economic benefit to the allocation of financial resources risk diversification and developing a complete financial system.

Financial business is one of the sectors that give much importance to AI because it helps to improve the efficiency of the financial industry faster by using AI as a way to help customers and commercial organizations connect easily and quickly. According to a study by Chinese public finance agencies (He and Guo,2018), the research shows that applying $\mathrm{AI}$ in financial businesses is also a threat to employment in banking, insurance, and equity markets, with a decreased by 23 percent in 2027 from 2017. Insurance employees will be the most affected, followed by the banking business, and the equities market. This study expects that Financial sectors of countries with large financial areas in ASEAN, such as Singapore Malaysia, Thailand, and the Philippines, are probably getting harder hit than the rest.

\subsection{Lack of The Legal Readiness of Data Privacy.}

Most ASEAN countries in ASEAN do not developed their legal regulation regarding data privacy when compared to their electronic transactions. Based on the IDRC indicators, only 6 countries have laws and / or 
ethical frameworks to protect privacy information from the use of AI; they are Singapore, Malaysia, Thailand, Indonesia and Vietnam. Lack of such legal is a hindrance to develop the digital economy in line with national development towards industrial 4.0 era (Table 3)

Table 3. Legal Principles and Ethical Frameworks for Protecting Privacy Information from AI

\begin{tabular}{ccc}
\hline ASEAN Country & Score & Ranking \\
\hline Brunei & 0.671 & 4 \\
Cambodia & 0.514 & 9 \\
Indonesia & 0.671 & 5 \\
Lao & 0.557 & 7 \\
Malaysia & 0.771 & 2 \\
Myanmar & 0 & 10 \\
Philippines & 0.729 & 3 \\
Singapore & 0.814 & 1 \\
Thailand & 0.629 & 6 \\
Viet Nam & 0.529 & 8 \\
\hline
\end{tabular}

Source. IDRC (2019). Government Artificial Intelligence Readiness Index 2019. Compiled by Oxford Insights and the International Development Research Centre.

\subsection{Weak in English Proficiency}

English is the language for ASEAN to work together. But the majority of the population is still weak in English. This problem hinders development through the IR4, because many educational resources related to digital technology are often provided in English. According to the English Proficiency Index (EFI,2019) ranking, it divides English language skills into five levels: very high level, high level, middle level, low level, and very low level. The result appears only Singapore, the Philippines, and Malaysia earn high scores and remain in the rank of Very high and high proficiency in English. Thailand's position is in the "very low proficiency," the same level as Myanmar and Cambodia, lower than in Indonesia and Vietnam, as shown in Table 4.

Table 4. Rank of English Proficiency Index for ASEAN

\begin{tabular}{ccc}
\hline 2018 Rank & Country & 2018 Band \\
\hline 5 & Singapore & Very High Proficiency \\
20 & Philippines & High Proficiency \\
26 & Malaysia & High Proficiency \\
52 & Vietnam & Low Proficiency \\
61 & Indonesia & Low Proficiency \\
74 & Thailand & Very Low Proficiency \\
86 & Myanmar & Very Low Proficiency \\
94 & Cambodia & Very Low Proficiency \\
\hline
\end{tabular}

$\overline{\text { Source. }}$ EF English Proficiency Index, $9^{\text {th }}$ edition. https://www.ef.co.th/epi/about-epi/

\subsection{Low Adoption Rate for AI in ASEAN's Manufacturing Sector}

Private entrepreneurs were increasingly adopting AI from 8 percent in 2017 to 14 percent in 2018 (IDC Asia / Pacific Enterprise Cognitive / AI survey, 2018). The most AI-based entrepreneurs in ASEAN are Indonesia, with 24.6 percent, followed by Thailand (17.1\%), Singapore (9.9\%), and Malaysia (8.1\%). The rate of adoption in AI technology is still low compared to North Asian countries. For example, more than $80 \%$ of companies in China and South Korea believe that the ability of AI will be essential for the success and competitiveness of the organization in the coming years. The main obstacle to access to AI technology is the lack of skills, knowledge and high costs (Fintech News, 2018). 


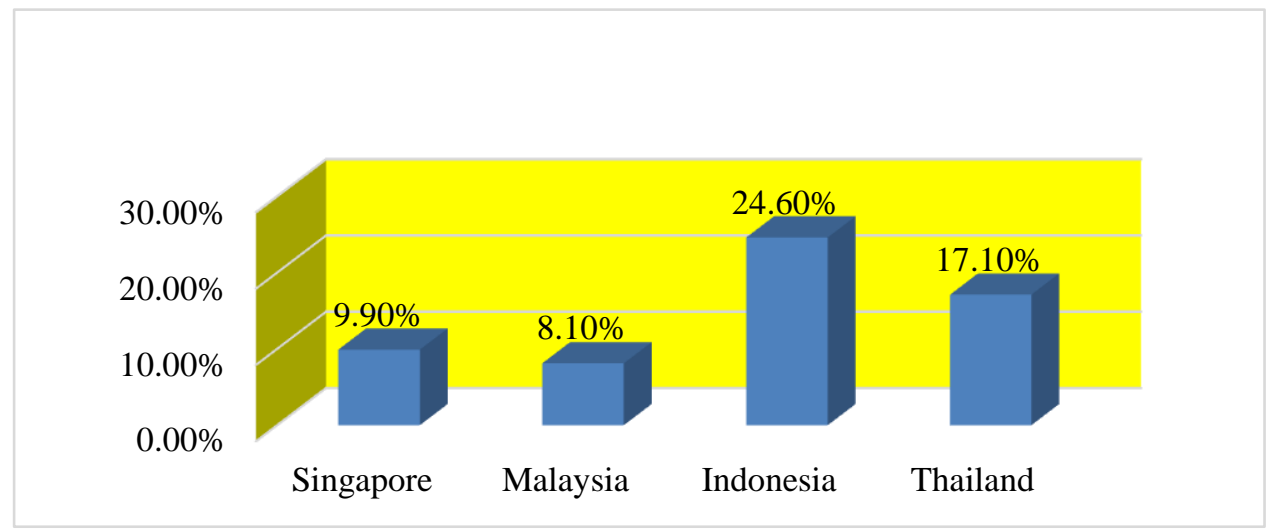

Figure 4. Adoption Rate of Using AI Technology of Business Sector in ASEAN

Source. Fintech News "Adoption of Artificial Intelligence on the rise in Asean, October 16, 2018.

\subsection{Adhering to Traditional Products and Services.}

Studies from the Association of Southeast Asian Nations have shown that producers in ASEAN, including Malaysia and Thailand, are in the early stages of digital investment. Management models are somewhat outdated, such as production competitiveness still bases on low labor costs, not interested in responding to customers' needs, working under an environment of insufficient information and connectivity. Also, most ASEAN entrepreneurs still believe in producing particular products or services that make a lot of money for the company, not interested in creating new products and services, resulting in only $25 \%$ on the average of products and services that were successful. And only $10 \%$ of companies can maintain long-term business growth; another $90 \%$ are unable to sustain their growth (Worawisut, 2009).

\subsection{Lack in Awareness of Insufficient Capacity in Innovation}

In the Global Competitiveness Report 2017/2018 by the World Economic Forum, there is one question asked the businessmen in all countries that "What are the problems in doing your business?". There are 16 categories for them to enter the number indicating the priority of each problem. The low rank shows that business people think that the problem is essential, and the high-level shows that it is less critical. Item 15, asking "Insufficient capacity to innovate," the results show that there are only four countries, namely Singapore, Thailand, Brunei, and Cambodia, aware that they have the insufficient capacity in innovation. The rest of them sees other problems more important than the lack of innovation. As shown in Table 5

Table 5. Rank of ASEAN Awareness in Their Insufficient Capacity in Innovation

\begin{tabular}{ccc}
\hline \multirow{2}{*}{ Country } & \multicolumn{2}{c}{ problematic factors (a) } \\
\cline { 2 - 3 } & rank & score \\
\hline Brunei & 4 & 12.2 \\
Cambodia & 7 & 6 \\
Indonesia & 15 & 2.5 \\
Lao & 12 & 4.2 \\
Malaysia & 11 & 5.4 \\
Myanmar & - & - \\
Philippines & 11 & 2.3 \\
Singapore & 2 & 22.4 \\
Thailand & 4 & 10.5 \\
Viet Nam & 15 & 2.5 \\
\hline
\end{tabular}

Note. This table produces by author; data derived from World Economic Forum, Executive Opinion Survey ใน The Global Competitiveness Report 2017-2018

\subsection{An Unexpected Growth of ASEAN Digital Economy in 2025}

The internet economies in Malaysia, Thailand, Singapore, and the Philippines are growing by between $20 \%$ and 
$30 \%$ annually, with no signs of slowing down. This is a remarkable feat compared to other regions. The two pacesetters in the region are Indonesia and Vietnam, which lead the pack with growth rates in excess of $40 \%$ a year (Google \& Temasek / Bain, e-Conomy SEA 2019).

Google and Temasek 2018 (Google \& Temasek, e-Conomy SEA, 2018) predicted that Southeast Asia's internet economy would create more than 1.7 million permanent jobs by 2025, three times as much as 2018 . The value of the digital economy of 6 major ASEAN markets, including Indonesia, Malaysia, Philippines, Singapore, Thailand, and Vietnam, will grow from \$ 50000 million to the US \$ 200000 million in 2025.

\subsection{Employment Threat}

Most ASEAN is still unable to adapt themselves to cope with the world's 4th Industrial Revolution. Using robots to work for people is considered a threat to unemployed workers. According to the Cisco and Oxford Economics study of the impact of AI on workers in six ASEAN countries, Singapore workers are likely to have the worst effect from AI usage in the next decade. With 1 in 5 of the full-time employees $(20.6 \%)$ will be replaced by AI in 2028, this figure is higher than Vietnam (13.8\%), Thailand (11.9\%), Philippines (10.1\%), Indonesia (8.1\%) and Malaysia (7.4\%). The workers in Singapore suffer from the problem of unemployment before other countries because it is more advances in the use of AI than any other country.

\subsection{Income Inequality in ASEAN}

Collective efforts by ASEAN and the UN have helped the region to achieve large gains in poverty reduction.

The number of people in extreme poverty in Southeast Asia declined from 138 million in 2000 to 44 million in 2015, and the UN Economic and Social Commission for Asia and the Pacific (Escap) predicts the figure will fall below 25 million by 2030 (Tanyatorn Tongwaranan,2018). However, there continue to be development gaps between countries and income gaps within countries. it is less successful in increasing the size of the middle class in bridging disparity gaps. The gaps are expected to widening rather than decreasing with the development of IR4. The poor continue to benefit the least from the gains of development within ASEAN.

\section{Results of the Study}

\subsection{SWOT Analysis}

This paper evaluates the readiness of the ASEAN Community for the world Fourth Industrial Revolution and recommends strategies for developing ASEAN towards the 4th Industrial Revolution (IR4). The results of the study for SWOT analysis are presented in Table 6.

Table 6. Results of the SWOT Analysis

\begin{tabular}{l} 
Strengths \\
\hline 1. ASEAN has high economic potential in GDP and GDP growth.
\end{tabular}

Weaknesses

1. Based on the IDRC indicators, only 6 countries have laws and/or ethical frameworks to protect privacy information in using AI.

2. The readiness of cooperation in innovation to enhance industrial readiness 4.0 has appeared in AEC Blueprint 2025

3. ASEAN is better equipped with artificial intelligence (AI) than the world average and the Asia Pacific (IDRC, 2019).

4. The population structure in ASEAN indicates their readiness to be accelerated to digital growth

5. ASEAN has the potential to reap the benefits of the digital economy via the internet

6. At least six member countries, namely Indonesia, Malaysia, Philippines, Thailand, Singapore, and Vietnam, aim to consolidate the financial group by 2020 (Vora-Sittha, 2016); reflecting a robust financial sector in 2020.

2. Lack of direction to develop into the IR4 in the long run; only Singapore, Malaysia, and Indonesia have a strategic plan for AI development.

3. The majority of ASEAN people are weak in English, which hinders the development of digital technology.

4. The adoption rate for AI in ASEAN's manufacturing sector is low.

5. Most ASEAN entrepreneurs still adhere to traditional products and services. Only $10 \%$ of companies can maintain long-term business growth.

6. Most entrepreneurs in ASEAN are not aware that they have the insufficient capacity in innovation.

7. The COVID-19 impact on ASEAN countries may slow down the pace of enhancing IR4 (speed up) 
8. Income inequality in ASEAN is expected to widening rather than decreasing with the development of IR4. This becomes detrimental for long term economic growth in ASEAN.

9. Most ASEAN is still unable to adapt themselves to cope with the world's 4th Industrial Revolution. Using robots to work for people is considered a threat to unemployed workers.

\begin{tabular}{|c|c|}
\hline Opportunities & Threats \\
\hline $\begin{array}{l}\text { 1. The size of the ASEAN digital economy has the opportunity to } \\
\text { be ranked as the world's top five in } 2025 \text {, led by Indonesia, } \\
\text { Malaysia, Philippines, Singapore, Thailand, and Vietnam }\end{array}$ & $\begin{array}{l}\text { 1. The robot is a threat to unemployment. The } \\
\text { workers in Singapore are expected to face the } \\
\text { problem of unemployment before other countries } \\
\text { because of its most advanced in using AI } \\
\text { technology. }\end{array}$ \\
\hline $\begin{array}{l}\text { 2. As one of the world industrial production center, ASEAN } \\
\text { countries with large industrial plants have the opportunity to apply } \\
\text { AI and IT to the production process for handling the limitations of } \\
\text { personnel and data storage. }\end{array}$ & $\begin{array}{l}\text { 2. The rapid expansion of electronic commerce } \\
\text { (E-Commerce) all over ASEAN is a threat to } \\
\text { wholesalers and retailers in the country. }\end{array}$ \\
\hline $\begin{array}{l}\text { 3. Small and medium enterprises have the opportunity to apply AI } \\
\text { technology for specific parts of the production process, and } \\
\text { develop their business in line with the broad industry. }\end{array}$ & $\begin{array}{l}\text { 3. AI technology affects employment in the financial } \\
\text { sector. }\end{array}$ \\
\hline $\begin{array}{l}\text { 4. E-commerce business has a high potential for expansion in } \\
\text { ASEAN. The leading markets are Indonesia, Singapore, and } \\
\text { Thailand with an expected total market share of } 74.96 \text { percent in } \\
2025 \text {. }\end{array}$ & $\begin{array}{l}\text { 4. The IR4 technology of the world is expensive, } \\
\text { entrepreneurs in ASEAN hesitate to invest, rather } \\
\text { than rushing to reap profits from new technology. }\end{array}$ \\
\hline $\begin{array}{l}\text { 5. Entering the IR } 4 \text { is an opportunity for ASEAN entrepreneurs to } \\
\text { use digital technology in increasing productivity and reduce the } \\
\text { problem of pressing labor costs. }\end{array}$ & $\begin{array}{l}\text { 5. The differences in the readiness of the } 4 \mathrm{IR} \text { of } \\
\text { ASEAN countries may come up with the risk of } \\
\text { having more disparity between ASEAN members. }\end{array}$ \\
\hline $\begin{array}{l}\text { 6. Currently, the world tries to coordinate data standards in data } \\
\text { supervision or the data protection framework between member } \\
\text { countries. It is an excellent opportunity for ASEAN member } \\
\text { countries to jointly push the Master Plan on ASEAN Connectivity } \\
2025 \text { to maintain the center and unity of ASEAN data transactions. }\end{array}$ & $\begin{array}{l}\text { 6. According to the Global Cybersecurity Index } \\
\text { (GCI) in 2018, most ASEAN countries do no } \\
\text { commit to cybersecurity, except Singapore, } \\
\text { Malaysia, Thailand, and Vietnam. }\end{array}$ \\
\hline
\end{tabular}

\subsection{TOWS Matrix Analysis}

The TOWS Matrix helps to identify and select one or more strategies to pursue. It works by taking each box from the SWOT and using them to form the TOWS as follows.

\section{Strengths and Opportunities (SO)}

Aiming at accelerating the size of its digital economy to be ranked world top 5 in the year by 2025, ASEAN should use e-commerce as a driving force for its expansion. ASEAN owes the internal strength of having a population structure already coping with digital growth. Following a Strengths-Opportunities framework, ASEAN also has an excellent opportunity for large industrial plants in ASEAN to cooperate in transferring AI technology in the production process. At the same time, small and medium-sized organizations can apply AI technology to specific parts of the production process.

\section{Weaknesses and Opportunities (WO)}

The majority of ASEAN is weak in English proficiency, An expectation of being the world's top five largest digital economies would be an incentive to enhance ASEAN English proficiency and digital skills. To improve the internal weaknesses of ASEAN both in English and digital competency, the government should use social media as a mechanism to keep them coping with the changing world. Besides, the government should put effort into the training program for their entrepreneurs' attitude; by changing their opinion from low prices of goods 
and wages towards the innovation of high productivity and low cost.

\section{Weaknesses and Threats (WT)}

The rapid expansion of electronic commerce (E-Commerce) is a threat to domestic wholesale and retail entrepreneurs. ASEAN governments should reap the benefits by collecting tax on e-commerce transactions thoroughly as a defensive strategy. Also, to help recede the risk for people who do not yet adjust to the cyber world, the countries that still lack cyber measures should hurry up in enacting legislation.

\section{Weaknesses and Opportunities (WO)}

To avoid threats and minimize weaknesses, the government should enact data privacy laws for reducing the risk of people who are not yet adapting to the cyber world. A Country that expedites the issuance of an AI strategic plan would be beneficial for its entrepreneurs to enhance their long-term investment in digital.

\section{Conclusions and Policy Recommendations}

For ASEAN, only Singapore is the readiest country to face with the 4IR. Most countries in ASEAN members moderately prepared for the world 4thIR, except Brunei, Cambodia, Laos, and Myanmar. The size of the ASEAN digital economy has the opportunity to be ranked as the world's top five in 2025, led by Indonesia, Malaysia, Philippines, Singapore, Thailand, and Vietnam. The population structure in ASEAN is ready to be accelerated to digital growth. The members have the potential to reap the benefits of the digital economy via the internet.

$\mathrm{AI}$ has the power to transform the way that governments around the world deliver public services. The capacity of governments to exploit the innovative potential of AI in ASEAN is better than the world average and the Asia Pacific. Indonesia, Thailand, Singapore, and Malaysia are the top that is most apply AI technology in ASEAN; at the rate of $24.6 \%, 17.1 \%, 99.9 \%$, and $8.1 \%$, respectively.

The robot is a threat to unemployed workers. Workers in Singapore may face the problem of unemployment before other countries because of its most advanced in using AI technology.

E-commerce business may have a high potential for expansion in ASEAN. The leading markets in this area are Indonesia, Singapore, and Thailand, with a total market share of 74.96 percent in 2025. One single market for ASEAN e-commerce and the online platform is a necessary condition for competing with the world e-commerce. Facilities for intraregional transportation and payment mechanism are required for the market to work.

ASEAN also has an excellent opportunity for large industrial plants in ASEAN to cooperate in transferring AI technology in the production process. At the same time, small and medium-sized organizations can apply AI technology to specific parts of the production process.

Readiness differences of the IR4 among ASEAN countries may come up with the risk of having more disparity between ASEAN members shortly.

ASEAN lacks cyber measures to prevent and reduce the risk of threats from outside countries.

The COVID-19 pandemic already accelerates digital transformation. This also happens in ASEAN as well as most parts of the world. Social distancing and public-private measures change people's lifestyles and working forms. Businesses and governments then rely more on technologies - and one quick step for IR-4 transformation in our opinion, to share and involve knowledge, news, information, goods, and services to likely change a "new normal" lifestyle in the public view as of 2020 and 2021.

\section{Acknowledgements}

This paper is part of a short research paper titled "Preparation and Progress of ASEAN Community Adaptation Towards The 4th Industrial Revolution of The World". The research was funded by the International Institute for Trade and Development (Public Organization) "ITD" in 2019. We humbly extend our thanks to ITD and all concerned persons who co-operated with us in this research work.

\section{References}

Ariffin, E. (2019). Can Industry 4.0 revolutionise manufacturing? The ASEAN POST, February 26,2019.

Class, M., \& Kharas, H. The Emerging Middle Class in Developing Countries. OECD Working Papers. No.285. https://dx.doi.org/10.1787/5kmmp8lncrns-en

Dess, G. (2018). Strategic Management. United States: McGraw-Hill. ISBN 9781259927621

Education First. (2019). EF English Proficiency Index (9th ed.). Retrieved from https://www.ef.co.th/epi/about-epi/ 
Disruptive Tech ASEAN. (2018). Adoption of artificial intelligence on the rise in ASEAN. Fintech News. October 16, 2018.

Google, Temasek, \& Bain, e-Conomy SEA. (2018). Southeast Asia's Internet economy hits an inflection point. e-Conomy SEA.

Google, Temasek, \& Bain, e-Conomy SEA. (2019). Swipe up and to the right: Southeast Asia's $\$ 100 B$ Internet economy in e-Conomy SEA 2019.

HE, D., \& Guo, V. (2018). 4 Ways AI will Impact the Financial Job Market. World Economic Forum (WEF). Retrieved

from https://www.weforum.org/agenda/2018/09/4-ways-ai-artificial-intelligence-impact-financial-job-market/

HRn ASIA. (2018). Workers in Singapore Worst Hit by AI Disruption in ASEAN. Retrieved from https://www.hrinasia.com/resource/workers-in-singapore-worst-hit-by-ai-disruption-in-asean/

IDRC. (2019). Government Artificial Intelligence Readiness Index 2019. Compiled by Oxford Insights and the International Development Research Centre.

ITU. (2017). Global Cybersecurity Index 2017. https://doi.org/10.1787/5d87fa05-en

Johns Hopkins University and Southeast Asian Health Ministries. Retrieved from https://www.csis.org/programs/southeast-asia-program/southeast-asia-covid-19-tracker-0

Lohatepanont, K. (2019). Cautious optimism on Asean's Digital Economy. Asia Focus. Jun 17, 2019.

Oxford Insights and the International Development Research Centre. (2019). Government Artificial Intelligence Readiness Index 2019. https://doi.org/10.1016/j.ijinfomgt.2019.08.002

Pantaweesak, N. (2019). AI enhances business potential Manufacturing industry in the 4.0 era. Economic Intelligence Center (EIC) Siam Commercial Bank.

Prachachart.net (2019). Where is Thai English in ASEAN. Retrieved from http://www.thai-aec.com/

Perrault, R. et al. (2019). The AI Index 2019 Annual Report. AI Index Steering Committee, Human-Centered AI Institute, Stanford University, Stanford, CA. December 2019. Retrieved from https://aipo-api.buddyweb.fr/app/uploads/2020/07/ai_index_2019_introduction.pdf

Schwab, K. (2016). The fourth industrial revolution: what it means, how to respond. World Economic Forum Global Agenda, 14 Jan 2016. https://doi.org/10.3390/joitmc4030021

Sing, C. (2018). A Resilient and Future-Ready ASEAN. ASEAN ECONOMIC INTEGRATION BRIEF. Minister for Trade and Industry of Singapore, Chair of the ASEAN Economic Ministers 2018. No. $04 /$ NOVEMBER 2018. Retrieved from https://asean.org/storage/2018/11/AEIB_4th-Issue_r1.pdf

The ASEAN Secretariat. (2015). ASEAN Economic Community Blueprint 2025. Jakarta, ISBN 978-602-0980-59-1

The ASEAN Secretariat. (2016). Master Plan on ASEAN Connectivity 2025. Jakarta, August 2016. ISBN 978-602-6392-02-2

The ASEAN Secretariat. (2019). ASEAN Integration Report 2019. Jakarta. October 2019. ISBN 978-602-5798-47-4

The Economic Times. (2017). Jun 28, 2017. Retrieved from http://economictimes.indiatimes.com/articleshow/ 59356453.cms?utm_source=contentofinterest\&utm_medium=text\&utm_campaign=cppst

The Stanford Institute for Human-Centered Artificial Intelligence. (2019). The AI Index 2019 Annual Report, AI Index Steering Committee, Human-Centered AI Institute, Stanford University, Stanford, CA, December 2019.

Tongwaranan, T. (2018). Inequality a growing challenge for rising Asean. ASIA FOCUS in The Bangkok Post. Published on 30 April 2018 at 04:30

UNIDO (2019). United Nations Activities on Artificial Intelligence (AI). Retrieved from https://www.itu.int/dms_pub/itu-s/opb/gen/S-GEN-UNACT-2019-1-PDF-E.pdf

Vora-Sittha, P. (2016). Is Thai Banking Ready for AEC Financial Liberalization in 2020?. Asian Social Science, 12(5), 226. https://doi.org/10.5539/ass.v12n5p226

Watkins, M. (2007). From SWOT to TOWS: Answering a Reader's Strategy Question. Harvard Business Review, March 27. 
Worawisut. (2009). Disruptive Innovation and Business Impact. Retrieved from https://worawisut.wordpress.com/2009/05/19/disruptive-technology-and-business/

World Economic Forum. (2018). Executive Opinion Survey. The Global Competitiveness Report 2017-2018.

Yoav Shoham, et al. (2018). The AI Index 2018 Annual Report. AI Index Steering Committee, Human-Centered AI Initiative, Stanford University, Stanford, CA, December 2018. Retrieved from http://cdn.aiindex.org/2018/AI\%20Index\%202018\%20Annual\%20Report.pdf

\section{Notes}

Note 1. Manufacturing system comprised of intelligent, autonomous, and decentralized factories

Note 2. For a given country, the relative skill group penetration is the ratio between the penetration rate of a given skill group in each country and the global average penetration rate.

\section{Copyrights}

Copyright for this article is retained by the author(s), with first publication rights granted to the journal.

This is an open-access article distributed under the terms and conditions of the Creative Commons Attribution license (http://creativecommons.org/licenses/by/4.0/). 